\title{
Optimal Factor and Commodity Taxation in a Small Open Economy
}

\author{
ANDREAS HAUFLER \\ Department of Economics and Statistics, University of Konstan;, Postfach 5560 18133, 12-78434 Konstanz, \\ Germany \\ ERRATUM: This paper originally published in International Tax and Public Finance, \\ 3: $425-442$ (1996) was inadvertently printed missing page 439 . This sequence of pages \\ corrects this error.
}


ventional second-best argument, i.e., the inability to tax profits or rents by means of other tax instruments. In a recent paper, Gordon and MacKie-Mason (1994) have taken a different route, explaining corporate income taxes by the need to prevent the conversion of labour income into otherwise untaxed corporate income. These differences in the basic view of the corporation tax may well affect the optimal adjustment of this tax in response to exogenous shocks, such as a change in the commodity tax regime. Therefore, an important task for future empirical analysis is to discriminate between the two competing-or complementary?-explanations of existing corporate income taxes.

\section{Appendix}

Proof of Proposition 2: Without loss of generality, assume that the fixed factor is $n_{2}$ while $n_{1}$ is elastically supplied. Uncompensated price effects are decomposed using the Slutsky equations

$$
\frac{\partial z}{\partial q_{2}}=\frac{\partial z^{C}}{\partial q_{2}}-c_{2} \frac{\partial z}{\partial y}, \quad \frac{\partial z}{\partial \omega_{1}}=\frac{\partial z^{c}}{\partial \omega_{1}}+n_{1} \frac{\partial z}{\partial y}, \quad \frac{\partial z}{\partial \omega_{2}}=n_{2} \frac{\partial z}{\partial y} \forall z \in\left\{n_{1}, c_{2}\right\}
$$

where a superscript $C$ denotes a compensated derivative, $y$ is nominal income and a change in $\omega_{2}$ causes only income, but no substitution effects. Using (A.1) in (17) and noting that $n_{2}$ is a constant gives

$$
\frac{\partial L}{\partial t_{n_{2}}}=n_{2} \theta-\mu_{2}=0, \quad \theta=\lambda\left(1-t_{c} \frac{\partial c_{2}}{\partial y}-\alpha_{1} \frac{\partial n_{1}}{\partial y}\right)-1 .
$$

and $\theta>0$ must hold if the revenue requirement $R_{0}$ excecds the maximal amount that can be collected by the lump sum tax $t_{n_{2}}$ (cf. Atkinson and Stiglitz, 1980, p. 373). From (A.2) it then immediately follows that $\mu_{2}>0$, i.e., the non-negativity constraint on the net return to the fixed factor is binding. From (21) then follows $t_{n_{2}}=w_{2}$, as stated in part (a) of the proposition.

To show Proposition 2(b), substituting the Slutsky relationships (A.1) into (16) and (17) gives

$$
\frac{\partial L}{\partial t_{c}}=c_{2} \theta+\lambda\left(t_{c} \frac{\partial c_{2}^{C}}{\partial q_{2}}+\alpha_{1} \frac{\partial n_{1}^{C}}{\partial q_{2}}\right)=0, \quad \frac{\partial L}{\partial t_{n_{1}}}=n_{1} \theta-\lambda\left(t_{c} \frac{\partial c_{2}^{C}}{\partial \omega_{1}}+\alpha_{1} \frac{\partial n_{1}^{c}}{\partial \omega_{1}}\right)=0 .
$$

where $\theta$ is given in (A.2) and $\alpha_{1}$ has been reduced to $t_{n_{1}}$ since $t_{x}=t_{k}=0$ (Proposition 1). Combining the two equations gives

$$
-t_{c}\left(\frac{1}{c_{2}} \frac{\partial c_{2}^{C}}{\partial q_{2}}+\frac{1}{n_{1}} \frac{\partial c_{2}^{C}}{\partial \omega_{1}}\right)=t_{n_{1}}\left(\frac{1}{c_{2}} \frac{\partial n_{1}^{C}}{\partial q_{2}}+\frac{1}{n_{1}} \frac{\partial n_{1}^{C}}{\partial \omega_{1}}\right)
$$


Using the assumption that leisure $\left(-n_{1}\right)$ and $c_{2}$ are net complements $\left(\partial c_{2}^{C} / \partial \omega_{1}=-\dot{\partial} n_{1}{ }^{\prime}\right.$, $\partial q_{2}<0$ ) shows that both tax rates must have the same sign. From the government budget constraint it then follows that $t_{c}$ and $t_{n_{1}}$ must both be positive.

Proof of Proposition 3: I tum first to the case where $t_{m_{2}}$ is constrained. Since $\pi_{1}=0$, equations (27) reduces to (23) as before. Solving for $t_{x}$ and substituting in (28) gives

$$
t_{k}=-\frac{1}{n_{2}}\left(\frac{\partial^{2} w_{2}}{\partial r^{2}}\right)^{-1} \frac{\partial w_{2}}{\partial r} \pi_{2}>0
$$

where (10) and $J=0$ from (25) have been used to sign $t_{k}$. Using (13) and (14) it then immediately follows from (27) that $\operatorname{sign}\left(t_{x}\right)=-\operatorname{sign}\left(t_{k}\right)=-1$.

The case where $t_{n}$, is constrained requires a few more steps. Substituting (27) in (28) and setting $\pi_{2}=0$ gives

$$
t_{k} n_{2} \frac{\partial^{2} w_{2}}{\partial r^{2}}=\pi_{l} \epsilon, \quad \epsilon=\frac{\partial^{2} w_{1} / \partial p_{1} \partial r}{\partial^{2} w_{1} / \partial p_{1}^{2}} \frac{\partial w_{1}}{\partial p_{1}}-\frac{\partial w_{1}}{\partial r}
$$

Using the zero-profit condition in sector I [cf. eq. (9)-(11)]

$$
p_{1} \frac{\partial w_{1}}{\partial p_{1}}-w_{1}+r \frac{\partial w_{1}}{\partial r}=0
$$

and expanding by $r$ gives

$$
\epsilon=\frac{1}{r}\left[\frac{\partial w_{1} / \partial p_{1}}{\partial^{2} w_{1} / \partial p_{1}^{2}}\left(r \frac{\partial^{2} w_{1}}{\partial r \partial p_{1}}+p_{1} \frac{\partial^{2} w_{1}}{\partial p_{1}^{2}}\right)-w_{1}\right]=-\frac{w_{1}}{r}<0,
$$

since $\partial w_{1} / \partial p_{1}$ is homogeneous of degree zero in $r$ and $p_{1}$. From (A.4) and (12) follows

$$
\operatorname{sign}\left(t_{k}\right)=-\operatorname{sign}\left(\pi_{1}\right)=-1 \text {. }
$$

Substituting (A.4) into (28) using (A.5) gives

$$
t_{x}=t_{k}\left(\frac{\partial^{2} w_{1}}{\partial p_{1}^{2}}\right)^{-1}\left[\frac{\partial^{2} w_{1}}{\partial r \partial p_{1}}-\frac{n_{2}}{n_{1}} \frac{r}{w_{1}} \frac{\partial w_{1}}{\partial p_{1}} \frac{\partial^{2} \boldsymbol{w}_{2}}{\partial r^{2}}\right]
$$

which can be signed from (11)-(14) to give sign $\left(t_{x}\right)=-\operatorname{sign}\left(t_{k}\right)=1$.

\section{Acknowledgments}

I have benefitted greatly from comments and suggestions by Max Albert, Johann K. Brunner, Bernd Genser, Ben Lockwood, Wilhelm Kohler, Jürgen MeckI, Guttorm Schjelderup 
(my discussant at the IIPF conference in Lisbon) and Günther Schulze. I also wish to thank two anonymous referees for their detailed and constructive comments. All remaining errors are exclusively my own.

\section{Notes}

1. The same is not true if all factors of production are intersectorally mobile (Heckscher-Ohlin assumption) and capital is also mobile internationally. In the Heckscher-Ohlin framework commodity trade equalizes gross-oftax factor prices between two countries as long as production in both countries is diversified. In the presence of (differential) capital taxation this is incompatible with investors' arbitrage, which equalizes net-of-tax rates of return to capital. As a consequence, a small open economy which levies non-zero taxes on capital (either directly or indirectly through product taxes) will produce only a single output good in the trade equilibrium (Sinn, 1990\%). This "knife-edge property" of the Heckscher-Ohlin trade model in the presence of factor mobility has long been known in the trade literature; see, e.g., Neary (1985) for a tetailed discussion.

2. This includes the possibility that a tax on worldwide interest income is nominally in place, but raises no revenue since all capical is invested abroad and no foreign income is reported. Frenkel, Razin and Sadka (1991, pp. 204206) show that even if a subset of countries (the members of the European Union, for exanple) agreed to cooperate in order to enforce the residence principle between them, the lack of coordination with the rest of the world will cause EU members to voluntarily forgo residence taxation.

3. What is exeluded throughout the analysis is a uniform commodity tax levied under a general tax principle, since these taxes conld be duplicated by an appropriate combination of factor taxes. A general destinationbased commodity tax is equivalent to an equal-rate tax on the two specific factors plus the capital endowment (thus containing a lump sum element). A general origin-based tax is instead equivalent to a tax an both specific factors and a source-based tax on capital. This also implies that a general production tax could be replicated by a general consumption tax and a equal-rate lax un capilal imports.

4. Note that this property does not depend on the assumption that the production factors $n_{1}$ and $n_{2}$ are sectorspecific and their supplies are determined independently. The profit maximization condition (8) hold equally in a Heckscher-Ohlin model, where a fixed amount of labour is perfectly mobile across sectors (in our notation $n_{1}+n_{2}=\bar{n}$ ).

5. In contrast, if a general production tax were levied, then the entire square bracket in (25) would be zero, i.e., an infinite number of combinations $\left(t_{k}, t_{x}\right)$ satisfies equations (23)-(24). This, of course, is an immediale imptication of the fact that a general production tax can be duplicated by an appropriate combination of factor taxes (cf. note 3 ).

6. The reason is that tuxes on specific factors, but not the taxes $t_{x}$ and $t_{k}$, affect the non-negativity constraints in (26). The production tax, for example, then has (by a multiple) all the effects of a specific tax on $n_{1}$, except for the negative term involving the Lagrange multiplier $\pi_{1}$.

7. This is a direct extension of the proof of Proposition 3. Intuitively, the combined tax instrument $t_{k}$ incorporates a direct tax of the fixed factor whereas $t_{x}$ can only tax $n$, indirectly. On the other hand. the combined capital tax also disforts production decisions in sector 2 , whereas the production tax does net. The choice between the two taxes thus implies trading off these comparative advantages.

8. More preciscly, this describes the present 'transitional system' of commodity taxation in Europe. The EU plans to switch to an international tax credit system cum clearing for its internal trade in 1997. The main effects of this change will be on the distribution of tax revenues across EU member states, however. Imports by traders will still effectively bear the tax rate of the destination country due to the recouping effeet of the international tax credit.

\section{References}

Atkinson, A.B. and J.E. Stiglitz (1980). Lectures on public economics. McGraw-Hill.

Bruce, N. (1992). "A note on the taxation of international capital income flows." Economic Record 68, $217-221$. 
Bucovetsky. S. and J.D. Wilson (1991). "Tax competition with two tax instruments." Regional Science and Urban Economics 21, 333-350.

Christiansen, V. ( 1994). "Cross-border shopping and the optimum commodity tax in a competitive and a monopoly market." Scandinavian Joumal of Economics $96,329-341$.

Diamond, P. and J.A. Mirrlees (1971). "Optimal taxation and public production I: Production efficiency." American Economic Review 61, 8-27.

Frenkel, J.A. A. Razin and E. Sadka (1991). International taxation in an integrated world. Cambridge: MIT Press.

Gordon, R.H. (1986). "Taxation of investment and savings in a world economy." American Economic Review 76, $1086-1102$.

Gordon, R.H. and J.K. MacKic-Mason (1994). "Why is there corporate taxation in a small open economy? The role of transfer pricing and income shifting," NBER Working Paper No. 4690 . Cambridge/Mass.

Haufler, A. (1993). Commedity ux harmonization in the European Community. Heidelberg: Physica.

Huizinga, H. and S.B. Nielsen (1995). "Capital income and profits taxation with foreign ownership of firms." EPRU Working Paper 1995-9. Copenhagen Business School.

Keen, M. (1993). "The welfare economies of tax co-ordination in the European Community: A survey." Fiscal Studies 14, 15-36.

Keen. M. and S. Lahiri (1994). "The comparison between destination and origin principles under imperfect competition." Working Paper W94/8. London: The Institute for Fiscal Studies.

Neary, J.P. (1985). "International factor mobility, minimum wage rates, and factor price equalization: A synthesis." Quarterly Journal of Economics 100, 551-570.

Sinn, H.-W. (1990a). "Can direct and indirect taxes be added for international comparisons of competitiveness?." In: H. Sicbert (ed.), Reforming cupital income taxation. Tübingen: Mohr, 47-65.

Sinn, H.-W, (1990b). "Tax harmonization and tax competition in Europe." European Economic Review 34, 489504.

Slemrod, J., C. Hansen and R. Procter (1994). "The seesaw principle in international tax policy." NBER Working paper No. 4867. Cambridge/Mass.

Sorensen, P.B. (1994). "From the global income tax to the dual income tax: Recent tax reforms in the Nordic countries." Intemational Tax and Public Finance 1, 57-79 